\title{
URGENSI PELESTARIAN DAN REHABILITASI MANGROVE BAGI MASYARAKAT DESA PANTAI MEKAR KECAMATAN MUARA GEMBONG
}

\author{
Ahnanto1, Erry Syahpirudin ${ }^{1}$, Indra Purba Waskita1, Novita1 ${ }^{1}$, Sri Hartati1, \\ Awaluddin Tjala2, Muhammad Zid² \\ ${ }^{1}$ Mahasiswa Program Studi PEP Program Pascasarjana UNJ \\ 2Dosen Pascasarjana UNJ \\ E-mail: muhammadzid@yahoo.com
}

\begin{abstract}
This study aimed to determine the role, functions and benefits of mangrove forests to people's lives, causing damage to mangrove ecosystems, as well as the efforts of preservation and rehabilitation of mangrove ecosystems, which have been, are being and will be done in the future in the village of Desa Pantai Mekar, Muara Gembong. This type of study is a qualitative research approach and deep insight into the survey with a view to understanding social situations, events, roles, or groups of specific interactions. This study uses a variety of techniques and a variety of instruments to collect data. Data analysis using descriptive qualitative techniques.

The results of the study were researchers from interviews get to the informant, discovered a few things related to the condition of the village before 1980 are as follows: (1) water of Citarum river can still be used to meet the needs drinking and cooking water. The condition water of Citarum River is still clean and healthy so there are no complaints about sore skin. (2) Harmonization ecosystem around Citarum River is still well preserved. Mangrove forests are broadly useful as a bastion of protection of coastal areas from the impact of flooding. (3) Prior to 1980, people never feel the flood, vast mangrove forests also provide benefits to fishermen because under mangrove forests store a lot offish habitat so that fishermen catch fish gained a lot and easy.

This study gives the conclusion that mangrove forests have a role, function and great benefits to people's lives Desa Pantai Mekar, Kecamatan Muara Gembong. The cause of the destruction of mangrove forests on there, due to occupational mangrove ponds, agricultural, residential location, fulfilling the need for firewood by the citizens, abuse of authority by purchasing land illegally forestry, forestry lack of supervisory personnel. Mangrove rehabilitation efforts have not been accompanied by proper preservation. The parties directly benefit from mangrove deforestation, not to replant immediately.
\end{abstract}

Keywords: mangrove forests, the urgency of preservation, rehabilitation.

\section{PENDAHULUAN}

Indonesia merupakan salah satu negara yang memiliki hutan mangrove terbesar dan memiliki kekayaan hayati yang paling banyak. Luas hutan mangrove di Indonesia mencapai 3,2 juta hektare, walaupun belakangan ini dilaporkan lebih dari 50 persen jumlah hutan itu sudah rusak. Luas hutan mangrove di Indonesia antara 2,5 hingga 4,5 juta hektar, merupakan mangrove yang terluas di dunia. Melebihi Brazil (1,3 juta ha), Nigeria (1,1 juta ha) dan Australia (0,97 ha) (Wikipedia). Sedangkan menurut Republika Online, bahwa Indonesia memiliki hutan bakau tropis terluas di dunia sekitar 3,8 juta hektar atau 40 persen dari total hutan bakau dunia. Jumlah hutan mangrove dunia di estimate sekitar 16 juta $\mathrm{Ha}$. Di Indonesia, hutan-hutan mangrove yang luas terdapat di seputar Dangkalan Sunda yang relatif tenang dan merupakan tempat bermuara sungai-sungai besar, yakni di pantai timur Sumatra, dan pantai barat serta selatan Kalimantan. Di pantai utara Jawa, hutan-hutan ini telah lama terkikis oleh kebutuhan penduduknya terhadap lahan (Arifin Arif, 2003: 12).

Menurut Arif (2003: 10) mangrove (Bakau) adalah jenis pohon yang tumbuh di daerah perairan dangkal dan daerah intertidal yaitu daerah batas antara darat dan laut 
dimana pengaruh pasang surut masih terjadi. Hutan mangrove atau disebut juga hutan bakau adalah hutan yang tumbuh di atas rawa-rawa berair payau yang terletak pada garis pantai dan dipengaruhi oleh pasang-surut air laut. Hutan ini tumbuh khususnya di tempat-tempat di mana terjadi pelumpuran dan akumulasi bahan organik. Baik di teluk-teluk yang terlindung dari gempuran ombak, maupun di sekitar muara sungai di mana air melambat dan mengendapkan lumpur yang dibawanya dari hulu. Ekosistem wilayah pantai berkarakter unik dan khas karena ekosistemnya perpaduan antara kehidupan darat dan air. Ekosistem wilayah itu memiliki arti strategis karena memiliki potensi kekayaan hayati baik dari segi biologi, ekonomi, bahkan pariwisata. Hal itu mengakibatkan berbagai pihak ingin memanfaatkan secara maksimal potensi itu.

Ekosistem hutan mangrove bersifat khas, baik karena adanya pelumpuran yang mengakibatkan kurangnya aerasi tanah; salinitas tanahnya yang tinggi; serta mengalami daur penggenangan oleh pasang-surut air laut. Hanya sedikit jenis tumbuhan yang bertahan hidup di tempat semacam ini, dan jenis-jenis ini kebanyakan bersifat khas hutan bakau karena telah melewati proses adaptasi dan evolusi. Akar tanaman mangrove berfungsi menstabilkan lumpur dan pasir. Di kawasan yang hutan manggrovenya telah dihancurkan untuk keperluan pembangunan, laju erosinya akan sangat tinggi. Hutan mangrove juga menjadi tempat hidup bagi habitat liar dan memberikan perlindungan alami terhadap angin yang kuat, gelombang yang dibangkitkan oleh angin (siklon atau badai), dan juga gelombang tsunami.

Menurut Purnobasuki di beberapa wilayah pesisir di Indonesia sudah terlihat adanya degradasi dari hutan mangrove akibat penebangan hutan mangrove yang melampaui batas kelestariannya. Hutan mangrove telah berubah menjadi berbagai kegiatan pembangunan seperti pertanian, pertambakan, pembangunan dermaga, dan eksploitasi mangrove itu sendiri. Hal seperti ini terutama terdapat di Aceh, Sumatera, Riau, pantai utara Jawa, Sulawesi Selatan, Bali dan Kalimantan Timur. Selanjutnya hutan mangrove di
Indonesia, menurut data yang ada telah banyak berkurang sejak digulirkannya program ekstensifikasi tambak dari 8,6 juta hektar hutan mangrove yang ada (terluas di dunia), sekitar 5,8 juta hektar (68\%) telah mengalami kerusakan yang serius, dimana salah satu penyebab utamanya adalah akibat ekstensifikasi tambak udang. Hal ini dilakukan karena kenaikan permintaan udang dari negara-negara di Eropa, Amerika dan Asia.

Kualitas lingkungan pesisir saat ini terus mengalami penurunan seiring dengan semakin meningkatnya jumlah penduduk di kawasan pesisir. Kenaikan jumlah penduduk di kawasan pesisir secara otomatis meningkatkan kebutuhan terhadap sandang, pangan, papan, air bersih dan energi, hal ini mengakibatkan eksploitasi terhadap sumber daya pesisir semakin meningkat. Dalam pengeksploitasiannya masyarakat cenderung mengabaikan aspek-aspek lingkungan dan bersifat merusak. Salah satu sumber daya pesisir yang saat ini mulai terancam adalah ekosistem mangrove yang mempunyai fungsi sebagai penyeimbang kawasan pesisir.

Menurut Sodikin, hutan mangrove Kecamatan Muara Gembong yang terletak di Pantai Utara Pulau Jawa dan terdapat satu kecamatan yang membatasi dengan DKI Jakarta yaitu Kecamatan Babelan, termasuk ke dalam kategori kawasan hutan lindung yang memiliki tingkat ancaman degradasi relatif tinggi. Menurut Kementerian Kehutanan pada tahun 2005 hutan mangrove di Kecamatan Muara Gembong terus mengalami berbagai tekanan, hampir 93,5 \% kawasan mangrove diokupasi masyarakat untuk keperluan tambak ikan, lahan pertanian, pemukiman, dan beberapa fasilitas sosial. Desa Pantai Mekar adalah salah satu desa yang berada di Kecamatan Muara Gembong Kabupaten Bekasi, di kawasan ini hutan mangrove dalam kondisi yang kritis, baik disebabkan oleh abrasi pantai, maupun adanya konversi lahan mangrove oleh masyarakat.

Sejak tahun 1990-an sampai saat ini, seiring semakin meningkatnya konversi lahan mangrove menjadi peruntukan lain, masyarakat mulai merasakan bahwa air sumur yang mereka konsumsi sudah terasa payau bahkan 
sudah terasa asin. Hal ini mengakibatkan masyarakat di Desa Pantai Bahagia sulit untuk mendapatkan air tawar untuk keperluan sehariharinya. Oleh karena itu penelitian ini dimaksudkan untuk mengetahui pengaruh kerusakan mangrove terhadap tingkat intrusi air laut serta pengaruhnya terhadap kehidupan masyarakat Desa Pantai Mekar Kecamatan Muara Gembong, Kabupaten Bekasi, Provinsi Jawa Barat.

\section{METODOLOGI PENELITIAN}

Penelitian ini bertujuan untuk mengetahui peranan, fungsi dan manfaat mangrove hutan mangrove bagi kehidupan masyarakat Desa Pantai Mekar, Kecamatan Muara Gembong, penyebab rusaknya ekosistem Mangrove di Desa Pantai Mekar, Kecamatan Muara Gembong, serta upaya dan rehabilitasi pelestarian Ekosistem Mangrove Desa Pantai Mekar, Kecamatan Muara Gembong yang telah, sedang dan akan dilakukan kedepannya. Penelitian dilakukan selama 3 (tiga) hari, sejak tanggal 25 Mei 2014 hingga 27 Mei 2014.

Pendekatan yang digunakan adalah kualitatif. Dalam penelitian ini data yang dicari dan dikumpulkan adalah berupa data primer dan data sekunder. Data primer adalah data yang berasal langsung dari wawancara dengan informan kunci. Informan kunci dalam penelitan ini adalah subjek dan sekaligus pelaku yang hidup dan tinggal di Desa Pantai Mekar kecamatan Muara Gembong, kabupaten Bekasi, Provinsi Jawa Barat. Data sekunder diperoleh melalui pihak kedua atau secara tidak langsung yang diperoleh dari beberapa dokumen, literatur, media masa serta petunjuk lainnya. Data sekunder ini dimaksudkan untuk memberikan gambaran umum serta untuk mendukung hasil penelitian ini.

Prosedur Pengumpulan data dalam penelitian ini adalah dengan melakukan observasi lapangan dan wawancara dan nutuk mengecek keabsahan data yang telah kami peroleh dari informan kunci, kami melakukan cross check dengan narasumber lain, yaitu anak-anak SD, ibu-ibu yang bertempat tinggal di sepanjang pesisir pantai serta tukang pembuat perahu. wawancara dilakukan secara tidak terstruktur atau dengan menggunakan teknik wawancara mendalam (indepht interview), serta dilakukan tidak secara formal terstruktur guna menggali pandangan subjek yang diteliti. Dan yang berikutnya dengan dokumentasi untuk memperoleh gambaran yang lengkap tentang kondisi dilapangan, meliputi data monografi, video wawancara dengan para informan serta foto observasi.

Analisis dan Interpretasi data berlangsung selama pengumpulan data dilakukan. Temuan yang bersifat deskriptif tersebut kemudian didiskusikan dengan nara sumber lain sebagai upaya validasi temuan. Peneliti juga melakukan teknik triangulasi data yaitu: pertama triangulasi dengan sumber, kedua, mengatasi dengan metode, dan yang ketiga, triangulasi dengan teori, yaitu peneliti mencari penjelasan pembanding terhadap hasil atau temuan penelitian. Hal ini dilakukan terutama berkenaan dengan pembahasan penelitian. Analisis data dilakukan secara kualitatif dengan langkah-langkah sebagaimana ditentukan oleh Miles dan Habermann (dalam Sugiyono, 2006: 336) melalui tahapan reduksi data, display data, dan penarikan kesimpulan.

\section{HASIL PENELITIAN}

Hasil penelitian di Desa Pantai Mekar Kecamatan Muara Gembong terhadap urgensi dan upaya rehabilitasi hutan mangrove meliputi gambaran Desa Pantai Mekar sebelum tahun 1980, gambaran Desa Pantai Mekar pada masa sekarang, bukti dampak positif mangrove, serta bukti dampak kerusakan mangrove terhadap kehidupan masyarakat di Desa Pantai Mekar Kecamatan Muara Gembong.

Berdasarkan hasil wawancara yang kami lakukan kepada informan, kami menemukan beberapa hal yang berhubungan dengan kondisi Desa Pantai Mekar Sebelum tahun 1980 diantaranya adalah sebagai berikut: (1) Air Sungai Citarum masih bisa digunakan untuk memenuhi kebutuhan air minum dan memasak. Kondisi air Sungai Citarum masih jernih dan tidak berbau. Warga Sungai Citarum bebas mandi dan mencuci di Sungai Citarum tanpa merasakan keluhan sakit kulit. (2) Harmonisasi ekosistem di sekitar Sungai Citarum masih terjaga dengan baik. Hutan mangrove yang 
luas berguna sebagai benteng perlindungan daerah pesisir dari dampak banjir pasang. (3) Sebelum tahun 1980, warga Desa Pantai Mekar tidak pernah merasakan banjir. Hutan mangrove yang luas juga memberikan keuntungan untuk nelayan karena di bawah hutan mangrove menyimpan habitat ikan yang banyak sehingga nelayan memperoleh tangkapan ikan yang banyak dan mudah. Peneliti juga menemukan sejumlah fakta dilapangan, dan telah kami lakukan konfirmasi kepada informan serta data sekunder berupa data monografi desa bahwa: (1) Jumlah penduduk di Desa Pantai Mekar terus mengalami peningkatan. Daerah hutan mangrove mulai beralih menjadi tempat pemukiman. Luas hutan mangrove semakin berkurang sehingga mengurangi benteng perlindungan dari abrasi air laut; (2) Pada tahun 2011 terjadi abrasi besar-besaran yang mengakibatkan kerusakan pada 40 (empat puluh) rumah tempat tinggal di area pesisir. Saat ini rumah tersebut sudah tidak berpenghuni; (3) Para pemilik rumah memilih untuk pindah dengan membeli lahan baru. Selain banjir karena pasang laut, warga juga harus menanggung kerugian akibat banjir musiman yang datang setiap tahun antara bulan Desember sampai Februari. Dampak dari banjir antara lain petani tambak merugi karena gagal panen dan warga mulai terkena penyakit; (4) Sejak tahun 1982, industri di Bekasi semakin berkembang. Warga mulai merasakan dampak pencemaran air dari pembuangan limbah industri. Air sungai menjadi bau. Warga sekitar aliran sungai tidak lagi menggunakan air sungai untuk memenuhi kebutuhan air minum dan memasak. Warga terpaksa membeli air bersih 1 dirigen (20 liter) seharga Rp.7000,00. Namun untuk kebutuhan MCK (mandi cuci kakus) warga tetap mengandalkan air sungai.; (5) Jumlah penduduk yang meningkat juga mengakibatkan perluasan wilayah pemukiman dan perluasan lahan tambak. Luas hutan mangrove berkurang dikarenakan mulai beralih fungsi menjadi wilayah pemukiman dan lahan tambak.; (6) Warga desa tidak menginginkan lahannya tetap ditanam mangrove karena khawatir jika lahannya menjadi hutan mangrove maka lahan tersebut diambil alih oleh pemerintah (Perhutani); (7) Dari hasil penelitian yang dilakukan oleh salah seorang warga yang aktif di LMDH (lembaga Masyarakat Desa Hutan) diketahui bahwa ternyata keberadaan hutan mangrove berdampak signifikan terhadap hasil tambak (ikan) yang dipelihara oleh warga.

Peneliti juga mengumpulkan sejumlah bukti positif dari keberadaan hutan mangrove di Desa Pantai Mekar Kecamatan Muara Gembong, bahwa seorang petani tambak yang bernama Bapak SF (38 tahun) memiliki kepedulian terhadap rehabilitasi mangrove. Di usianya yang tergolong muda, Bapak SF berupaya membuktikan kepada kelompok tua bahwa keberadaan pohon mangrove di tambak tidak akan mengganggu produksi tambak, justru sebaliknya. Bapak SF memiliki tambak ikan bandeng. Pada umumnya ikan bandeng bisa mencapai berat $150 \mathrm{gr}$ setelah berusia 6-9 bulan. Namun Bapak SF bisa memanen bandeng seberat $150 \mathrm{gr}$ hanya dalam kurun waktu 2 bulan. Bapak SF menjelaskan tentang fenomena tersebut bahwa di dalam area tambak Bapak SF terdapat pohon mangrove. Bapak SF tidak membuang pohon mangrove ketika membangun tambak ikan bandeng. Akar pohon mangrove ternyata menyimpan makanan yang berguna untuk pakan ikan bandeng. Kondisi tersebut membuat ikan bandeng jadi cepat tumbuh besar karena ikan bandeng tidak hanya memperoleh pakan dari petani tambak saja. Dampak positif lainnya dari pencemaran air sungai karena limbah bisa dinetralisir apabila menambah luas hutan mangrove. Karena akar mangrove mampu mengikat racun-racun yang terkandung dalam limbah.

Peneliti juga menemukan dampak kerusakan mangrove yang terjadi di Desa Pantai Mekar Kecamatan Muara Gembong berupa: (1) Kerusakan rumah akibat abrasi air laut Bencana abrasi pada tahun 2011, mengakibatkan kerusakan pada empat puluh rumah warga Desa Pantai Mekar. Pada saat bencana itu terjadi, tidak semua warga bisa langsung meninggalkan rumah tersebut dikarenakan mereka tidak memiliki uang untuk membeli lahan baru. Keluarga yang tetap bertahan disana, membuat anak-anak mereka terpaksa putus sekolah karena tidak ada akses 
jalan dari rumah menuju sekolah sekolah; (2) Kerusakan gedung akibat abrasi air laut yang pada awalnya bangunan ini merupakan kantor camat. Namun abrasi dan banjir pasang air laut telah merusak komponen bangunan tersebut sedikit demi sedikit sampai pada akhirnya bangunan tersebut tidak bisa dipergunakan lagi. Pengkroposan komponen bangunan disebabkan oleh tingginya kadar garam yang terbawa sampai ke bangunan tersebut saat terjadinya abrasi atau banjir pasang air laut. Andaikan luas kawasan hutan mangrove tetap ditingkatkan maka pohon mangrove bisa menjadi filter terhadap kandungan garam air laut; (3) Ketersediaan air bersih berkurang, bahwa sebelum tahun 1980, air muara Sungai Citarum masih bisa dipakai untuk memenuhi kebutuhan air minum dan memasak. Bahkan menurut keterangan warga yang sudah berumur sepuh, menjelaskan bahwa pada saat dirinya masih kanak-kanak atau sekitar tahun 1950, air muara Sungai Citarum bisa dikonsumsi lansung tanpa harus dimasak terlebih dahulu. Namun pada masa sekarang ini, air sungai sudah menjadi asin. Kualitas air seperti itu kurang sehat untuk dikonsumsi. Kebutuhan air bersih diperoleh dengan membeli air galon seharga Rp. 7000,00. Pedagang air bersih mengambil air bersih ke Cilincing, Jakarta Utara dengan menggunakan kapal. Air sungai menjadi asin dikarenakan debit air laut lebih besar daripada debit air sungai. Apabila debit air laut semakin tinggi sebaiknya luas hutan mangrove juga ditingkatkan supaya bisa menjadi filter kandungan garam air laut yang mengarah ke sungai; (4) Kerusakan innfrastruktur jalan diakibatkan abrasi dan banjir pasang air laut akses jalan menjadi rusak. Kondisi tersebut mengganggu mobilitas warga. Jalan yang rusak membahayakan pengguna kendaraan bermotor. Selain itu, jalan tersebut juga dipakai untuk akses anak sekolah menuju ke sekolah. Apabila jalan digenangi air terlalu tinggi maka anak-anak tidak berani berangkat ke sekolah dikarenakan takut terhadap bahaya gigitan ular laut. Kondisi tersebut mengakibatkan tingginya angka putus sekolah.

Hasil temuan penelitian kualitatif yang peneliti lakukan meliputi hambatan pelaksanaan rehabilitasi mangrove, tantangan rehabilitasi mangrove, upaya pemerintah dalam menjaga kelestarian hutan mangrove, serta pemecahan masalah atas rusaknya hutan mangrove. Pengetahuan warga tentang manfaaat mangrove masih terbatas, sebagian warga mengetahui bahwa pohon mangrove merupakan tanaman yang banyak manfaat. Namun warga Desa Pantai Mekar belum banyak yang memahami manfaat keberadaan mangrove. Kurangnya pengetahuan warga tentang manfaat mangrove membuat warga menebang mangrove demi kepentingan pribadi atau kelompok tertentu. Contohnya petani tambak, menebang pohon mangrove ketika akan membuka lahan tambak. Warga menebang pohon mangrove untuk mengambil batang yang akan dijadikan kayu bakar. Hal yang disayangkan lagi bahwa pohon mangrove yang ditebang warga adalah pohon mangrove yang berusia di atas 3 tahun. Padahal pohon mangrove yang sudah berusia tiga tahun memiliki akar yang besar dan banyak sehingga berguna sebagai tempat habitat mahluk hidup seperti ikan, burung, kera, dan lain-lain.

Penyalahgunaan wewenang oleh oknum pemerintah, dengan membeli area hutan mangrove dan dijadikan lahan tambak namun warga tidak berani melarang karena takut melawan otoritas pejabat. Seorang warga menjelaskan bahwa pohon mangrove yang berada di hadapan peneliti merupakan hasil penanaman yang dilakukan oleh suaminya bertahun-tahun yang lalu tetapi sekarang ini pohon mangrove tersebut telah mati. Pohon mangrove sengaja dimatikan karena area tersebut akan berubah fungsi menjadi area tambak udang. Penyalahgunaan dana rehabilitasi.

Kondisi kerusakan hutan mangrove di Desa Pantai Mekar menarik perhatian banyak pihak. Lembaga atau perusahaan dalam dan luar negeri turut berpartisipasi dalam menyediakan dana rehabilitasi hutan mangrove. Namun sangat disayangkan, ada pihak yang mengambil keuntungan demi dirinya sendiri sehingga dana rehabilitasi tidak tepat sasaran. Disamping kesadaran semua pihak, keterbatasan personil polisi hutan juga dinilai menjadi kendala dan penyebab menyusutnya 
lahan dimana dari luas lahan hutan mangrove yang mencapai mencapai 10.480 hektare hanya dijaga oleh 27 orang yang terdiri dari 3 resort. Data kami peroleh dari studi penelitian tesis atas nama Zainal Rahman Dilaga dengan Judul pengelolaan Hutan Mangrove Dalam Upaya Pengendalian Pelestarian Lingkungan.

Tantangan yang dihadapi dalam upaya rehabilitasi mangrove diantaranya adalah warga kurang berpartisipasi menanam mangrove di lahan miliknya dikarenakan takut kehilangan hak kepemilikan lahan jika lahan tersebut menjadi hutan mangrove. Ketakutan tersebut didasari oleh ajaran tradisi turun temurun dari generasi pendahulu. Oleh karena hal tersebut perlu adanya ketetapan hukum yang jelas terhadap kepemilikan lahan. Disain kegiatan penanam Mangrove dikemas sehingga bernilai sebagai rekreasi. Menurut WWF Indonesia 2013, kawasan pesisir yang ditanam mangrove belum mencapai sepuluh persen. Penanaman mangrove tidak bisa hanya mengandalkan warga sekitar pesisir saja, perlu adanya dukungan tenaga dan materi dari pihak luar atau wisatawan. Pekerjaan warga Desa Pantai Mekar pada umumnya adalah pedagang, petani tambak dan nelayan. Jadi perlu adanya mata rantai ekonomi yang bisa bisa membuat warga berpartisipasi melakukan pembibitan mangrove.

Upaya pemerintah dalam menjaga kelestarian hutan mangrove adalah pihak Perhutani telah melakukan berbagai upaya dengan masyarakat untuk membantu menjaga hutan dengan bentuk kemitraan agar pengawasan hutan bisa dibantu oleh masyarakat sekitar. Perhutani juga terus melakukan penanaman bibit mangrove yang dibantu oleh pemerintah daerah maupun perusahaan yang peduli terhadap keberadaan dan pelestarian hutan bakau.

Untuk konservasi hutan mangrove dan sempadan pantai, Pemerintah RI telah menerbitkan Keppres No. 32 tahun 1990. Sempadan pantai adalah kawasan tertentu sepanjang pantai yang mempunyai manfaat penting untuk mempertahankan kelestarian fungsi pantai, sedangkan kawasan hutan mangrove adalah kawasan pesisir laut yang merupakan habitat hutan mangrove yang berfungsi memberikan perlindungan kepada kehidupan pantai dan lautan.

Sempadan pantai berupa jalur hijau adalah selebar $100 \mathrm{~m}$ dari pasang tertinggi kearah daratan. Upaya-upaya yang dapat dilakukan untuk memperbaiki dan melestarikan hutan mangrove antara lain: (1) Penanaman kembali mangrove sebaiknya melibatkan masyarakat. Modelnya dapat masyarakat terlibat dalam pembibitan, penanaman dan pemeliharaan serta pemanfaatan hutan mangrove berbasis konservasi. Model ini memberikan keuntungan kepada masyarakat antara lain terbukanya peluang kerja sehingga terjadi peningkatan pendapatan masyarakat; (2) Pengaturan kembali tata ruang wilayah pesisir: pemukiman, vegetasi, dll. Wilayah pantai dapat diatur menjadi kota ekologi sekaligus dapat dimanfaatkan sebagai wisata pantai (ekoturisme) berupa wisata alam atau bentuk lainnya; (3) Peningkatan motivasi dan kesadaran masyarakat untuk menjaga dan memanfaatkan mangrove secara bertanggungjawab; (4) ljin usaha dan lainnya hendaknya memperhatikan aspek konservasi; (5) Peningkatan pengetahuan dan penerapan kearifan local tentang konservasi; (6) Peningkatan pendapatan masyarakat pesisir; (7) Program komunikasi konservasi hutan mangrove; (8) Penegakan hukum; (9) Perbaikkan ekosistem wilayah pesisir secara terpadu dan berbasis masyarakat. Artinya dalam memperbaiki ekosistem wilayah pesisir masyarakat sangat penting dilibatkan yang kemudian dapat meningkatkan kesejahteraan masyarakat pesisir. Selain itu juga mengandung pengertian bahwa konsep-konsep lokal (kearifan lokal) tentang ekosistem dan pelestariannya perlu ditumbuh-kembangkan kembali sejauh dapat mendukung program ini.

\section{KESIMPULAN}

Penelitian ini menyimpulkan bahwa jelas adanya manfaat hutan mangrove bagi kehidupan masyarakat Desa Pantai Mekar, adalah masa panen ikan bandeng jadi lebih singkat. Pada sisi lain timbul dampak akibat kerusakan hutan mangrove, diantaranya persediaan air bersih berkurang, akses jalan menjadi rusak karena abrasi, bangunan kantor 
camat dan rumah penduduk mengalami kerusakan parah,serta tangkapan nelayan berkurang.

Kegiatan rehabilitasi mangrove belum berjalan optimal dikarenakan pengetahuan warga tentang mangrove masih terbatas, ada penyalahgunaan wewenang oleh oknum pemerintah, ada penyelewengan dana rehabilitasi, dan kurangnya tenaga kepengawasan dari perhutani. Selain hambatan yang perlu diminimalisir, ada juga tantangan yang harus ditanggulangi yaitu status kepemilikan lahan warga perlu memperoleh dasar hukum, kegiatan penanaman mangrove perlu didesain menjadi kegiatan yang bersifat rekreasi, dan pembibitan mangrove harus mengarah pada nilai ekonomis.

Upaya yang telah dilakukan oleh pemerintah yaitu menjalin kerjasama dengan masyarakat untuk berpartisipasi menjaga kelestarian hutan mangrove dengan melakukan pembibitan mangrove, dan meyakinkan pihak perusahaan untuk mendonasikan dana CSR pada program pelestarian mangrove.

Pemecahan masalah rusaknya hutan mangrove yaitu dengan membuat gerakan penanaman kembali mangrove, pengaturan ulang tata ruang wilayah pesisir, peningkatan motivasi dan kesadaran masyarakat untuk menjaga dan memanfaatkan mangrove secara bertanggungjawab, ljin usaha dan lainnya hendaknya memperhatikan aspek konservasi, peningkatan pengetahuan dan penerapan kearifan local tentang konservasi, Peningkatan pendapatan masyarakat pesisir, program komunikasi konservasi hutan mangrove, Penegakan hukum, serta perbaikan ekosistem wilayah pesisir secara terpadu dan berbasis masyarakat.

\section{DAFTAR PUSTAKA}

Arief, Arifin, Hutan Mangrove: Fungsi dan Manfaatnya. Yogyakarta: Canisius, 2003.

Departemen Kehutanan, 1998. Pengenalan Jenis Tanaman Mangrove. Balai Rehalibitas Lahan dan Konservasi Tanah. 1998.

Moleong, J.L., Metode Penelitian Kualitatif. Bandung: Remaja Rosdakarya, 2010

Purnobasuki, Hery, Kurangi Dampak Tsunami dengan Konversi mangrove. Depatemen Biologi FST, Universitas Erlangga (http://www.akademia.edu) diakses 25 Juni 2014.

Sodikin, Kerusakan Mangrove serta korelasinya dengan Tingkat Intrusi Air Laut. (http://geoenvironment.blogspot.com)

Soegiono, Metode Penelitian Pendidikan. Bandung: Alphabeta, 2010. 